\title{
Distension of the gall bladder inhibits sphincter of Oddi motility in humans
}

\author{
A Thune, G T P Saccone, J P Scicchitano, J Toouli
}

\begin{abstract}
Studies in animals have suggested a neural reflex between the gall bladder and the sphincter of Oddi. The aim of this study was to investigate whether sphincter of Oddi motility is altered by distension of the gall bladder in humans. Sphincter of Oddi motility was recorded intraoperatively in 10 patients undergoing elective cholecystectomy for gall stones. The manometry was performed by a triple lumen constantly perfused catheter which was introduced through the cystic duct and positioned across the sphincter of Oddi to record sphincter basal pressure, wave amplitude, and frequency of contractions. In five patients a separate catheter was introduced into the gall bladder after ligation of the cystic duct. This catheter was used to distend the gall bladder. Sphincter of Oddi pressures were measured before, during, and after the distension. In a separate control group of patients $(n=5)$ basal sphincter of Oddi activity was recorded without distension of the gall bladder. Distension of the gall bladder decreased sphincter of Oddi basal pressure from (mean (SD)) $22.8(8.5)$ $\mathrm{mmHg}$ to $18.6(6.5) \mathrm{mmHg}(\mathrm{p}=0.01$, paired $t$ test) and frequency of sphincter of Oddi contractions decreased from $2.6(1.6)$ to $1.1(1.3)$ contractions $/ \mathrm{min}$ ( $\mathrm{p}=0.003$, paired $t$ test). The results were significantly different from those of the control group ( $<<0.05$, unpaired $t$ test) during the same time period (four minutes). Pulse rate and blood pressure were not affected by the gall bladder distension. The results suggest a local reflex between the gall bladder and the sphincter of Oddi that might be important in the regulation of the pressure within the bile ducts and flow across the sphincter. This reflex is likely to be neurally mediated and injuries to it may be important in the aetiology of postcholecystectomy sphincter of Oddi dysfunction.
\end{abstract}

In animal experiments it has been shown that the sphincter of Oddi has a complex nervous innervation, which includes adrenergic excitatory and inhibitory nerves, cholinergic nerves with uncertain function as well as a non-cholinergic, non-adrenergic inhibitory innervation. ${ }^{1-4}$ In recent animal experiments a local reflex of the sphincter of Oddi has been identified. Distension of the gall bladder or increased pressure in the bile ducts reduced the flow resistance across the sphincter of Oddi in the cat. ${ }^{5-7}$ This effect was shown to be mediated through a neural pathway as topical anaesthesia and administration of tetrodotoxin abolished the reflex. ${ }^{5}$ Previous studies had shown other reflexes which may influence sphincter of Oddi motility. This includes reflexes which originate from the stomach, ${ }^{6}$ duodenum, ${ }^{68}$ and pancreatic duct. ${ }^{8}$ Anatomical studies have shown that the wall of the gall bladder has a network of nerves similar to the myenteric plexus of the intestine and there are axonal projections to the duodenum and the sphincter of Oddi. ${ }^{9}$

Although evidence is accumulating that these reflexes are present in a variety of species, their presence in humans has not been shown. The aim of this study was to determine whether the reflex between the gall bladder and sphincter of Oddi is present in humans, and if so, what effect might be produced on its motility by distension of the gall bladder.

\section{Methods}

Ten patients (median age 38 years, range $20-74$ years) undergoing elective cholecystectomy for gall stone disease were studied. The patients received no opiates or anticholinergic drugs before the study. Diazepam, 10-20 mg orally, was given as premedication. Anaesthesia was induced with thiopentone sodium, 3-5 mg/kg and maintained with enflurane, $1-4 \%$ in nitrous oxide and oxygen (2:1). Intubation and artificial ventilation of the lungs were facilitated by vecuronium. Pulse and blood pressure were continuously measured during the procedures.

The operation was performed through a subcostal incision. The gall bladder was not handled excessively with instruments and dissection in Calot's triangle was minimised and restricted to identifying the cystic duct. The cystic artery was not initially ligated nor was there any dissection near the bile duct. The cystic duct was identified and ligated at its junction with the neck of the gall bladder. An incision was then made on the cystic duct in order to insert the catheter for the cholegram and subsequently for the manometry catheter.

In view of the requirement that only minimal dissection be performed in Calot's triangle before ligating the cystic duct, only patients with minimal inflammation and thickening of the gall bladder were selected for this study. The anatomical arrangement of the ducts and vessels

TABLE I Mean (SD) basal pressure, mean frequency of contractions, and mean amplitude of contractions during initial two minute period

\begin{tabular}{lcc}
\hline & $\begin{array}{c}\text { Study } \\
\text { group }\end{array}$ & \multicolumn{2}{c}{$\begin{array}{l}\text { Control } \\
\text { group }\end{array}$} \\
\hline No of patients & 5 & 5 \\
Common bile duct pressure (mmHg) & $8 \cdot 0(5 \cdot 2)$ & $9 \cdot 6(3 \cdot 1)$ \\
Basal pressure (mmHg) & $22 \cdot 8(8 \cdot 5)$ & $29 \cdot 9(8 \cdot 3)$ \\
Frequency (contractions/min) & $2 \cdot 6(1 \cdot 6)$ & $2 \cdot 9(1 \cdot 9)$ \\
Amplitude (mmHg) & $101 \cdot 6(44 \cdot 3)$ & $94 \cdot 0(57 \cdot 7)$ \\
\hline
\end{tabular}

Values are mean $(\mathrm{SD})$
Flinders Medical Centre, Bedford Park, South Australia G T P Saccone J P Scicchitano J Toouli

Correspondence to: Professor J Toouli.

Accepted for publication 3 August 1990 


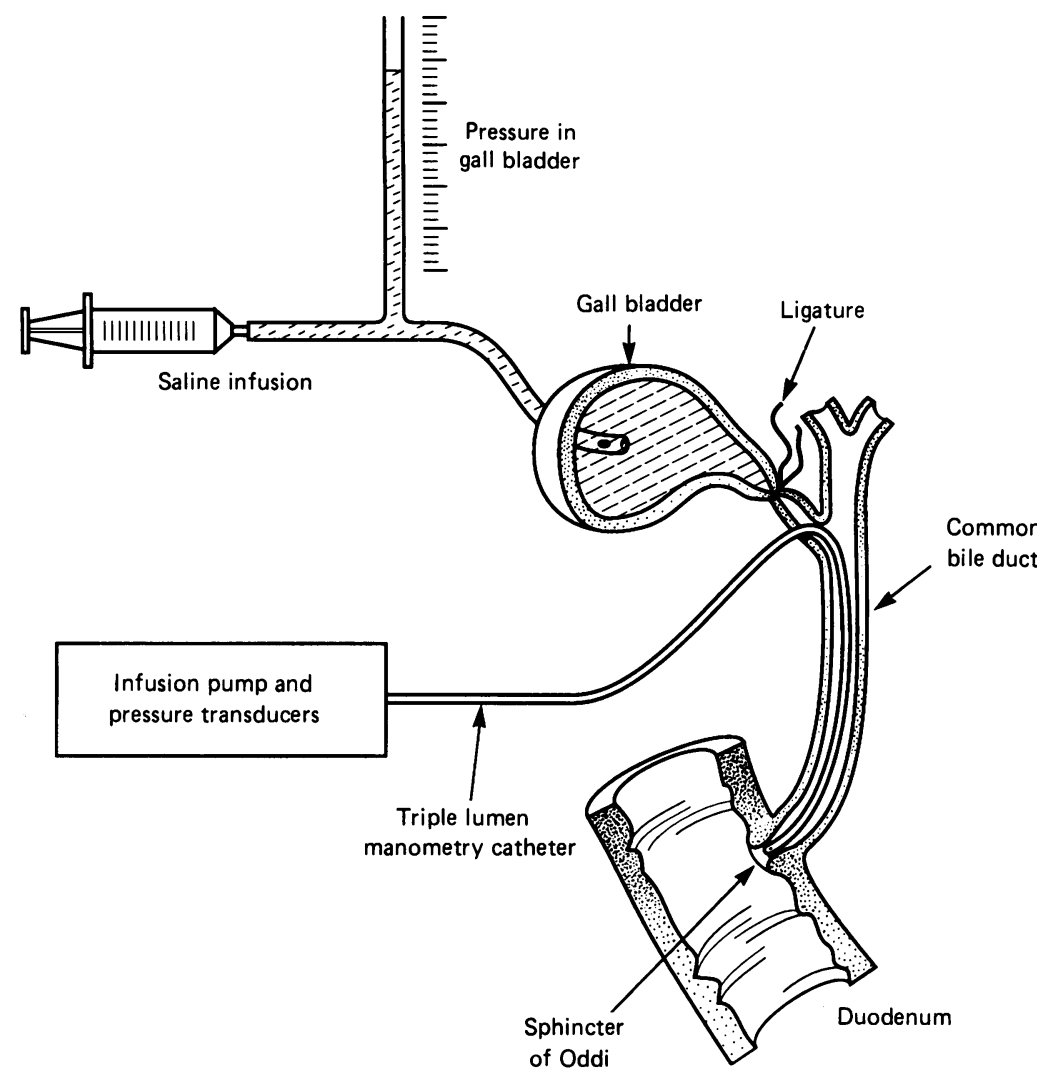

Figure 1: Schematic representation of the method used for distending the gall bladder and measurement of sphincter of Oddi motility. The catheter placed in the gall bladder was secured by a purse string suture. Saline was infused by the syringe and the pressure within the system measured from the height of the fluid level in the side-arm manometer. The manometry catheter was passed through the cystic duct and positioned across the sphincter of Oddi.

could be identified through the thin layer of peritoneum and did not necessitate extensive dissection.

Operative cholegram was performed and the manometric study was then carried out while awaiting development of the cholegram. On completion of the study, the cholecystectomy was done in the usual manner. No complications attributable to the study were recorded in these patients.

\section{INTRAOPERATIVE MANOMETRY}

The procedure for intraoperative manometry of the sphincter of Oddi has been previously reported. ${ }^{10}$ Briefly, a triple lumen polyethylene manometry catheter of $200 \mathrm{~cm}$ length and with $1.5 \mathrm{~mm}$ outer diameter was used to record pressures. The three recording side holes in the distal end of the catheter were situated $2 \mathrm{~mm}$ apart. Each catheter lumen was infused with sterile water at a flow rate of $0.25 \mathrm{ml} / \mathrm{min}$ by a minimally compliant hydraulic capillary infusion system. The changes in pressures within the sphincter of Oddi were recorded on a polygraph recorder. The polygraph recorder was calibrated so that zero pressure was recorded at the level of the bile duct.

DISTENSION OF THE GALL BLADDER

In five subjects sphincter of Oddi manometry was performed before, during, and after distension of the gall bladder. On completion of the operative cholegram, the gall bladder was emptied by a stab incision on the fundus and the open end of a three way central venous line catheter inserted into the lumen of the gall bladder (Fig 1). The catheter was secured by a purse string suture. The gall bladder catheter had been previously fashioned with a side hole, $1 \mathrm{~cm}$ from its tip so as to avoid occlusion against the mucosa of the gall bladder. The sphincter of Oddi manometry catheter was introduced through the cystic and bile duct into the duodenum and was withdrawn in a step-wise fashion so that all three side holes were located in the sphincter of Oddi. The position of the catheter in the sphincter of Oddi was confirmed by observation of the characteristic pressure changes on the recording. ${ }^{10}$

Sphincter of Oddi pressures were recorded initially for a baseline period of two minutes with the gall bladder empty. The pressure was then increased for two minutes by filling the gall bladder with the same volume of saline as the volume of bile aspirated at the beginning of the experiment. One to two $\mathrm{ml}$ of saline over and above the volume of bile aspirated was added as necessary to achieve subjective distension of the gall bladder. The volume of bile aspirated was (mean (SD)) $20.6(6.2 \mathrm{ml})(\mathrm{n}=5)$. In four of the five subjects distension of the gall bladder was monitored by estimating the intraluminal pressure in the gall bladder by a side-arm manometer which recorded the height of the level of saline above the gall bladder (Fig 1). The study was then completed by recording for a further two minute period after the gall bladder had been re-emptied

In five different subjects sphincter of Oddi pressures were recorded during a four minute period which corresponded in time to the period of the gall bladder distension experiments. During this period the gall bladder was not manipulated and the intraluminal pressure was not altered in any way. Data from these subjects provided the 'control' pressure measurements. Intraoperative biliary manometry was approved by the Clinical Investigations Committee of Flinders Medical Centre in 1982, with informed written consent obtained from all patients.

\section{ANALYSIS OF TRACINGS}

The manometric tracings were scored for sphincter of Oddi basal pressure $(\mathrm{mmHg})$, amplitude ( $\mathrm{mmHg}$ ), and frequency of contractions (contractions/min). Basal pressure and amplitude of contractions were calculated as the mean values of the three recording channels above duodenal pressure. An increase in pressure in excess of twice basal pressure was classified as an sphincter of Oddi contraction. Pressure peaks below this or with contraction rates exceeding $300 \mathrm{mmHg} / \mathrm{s}$ were considered as artifacts." The frequency, mean basal pressure, and mean amplitude of contractions were calculated for each two minute period.

\section{STATISTICAL ANALYSIS}

The mean value during each two minute recording period was used as a single value in the calculations. All data are represented as the mean 
(SD) unless otherwise stated. Analysis was performed using the one tailed paired $t$ test to evaluate changes within the same subjects and the one tailed unpaired $t$ test for comparison between the separate groups. A p value less than or equal to 0.05 was regarded as significant.

\section{Results}

The mean basal pressure, mean frequency of contractions, and mean amplitude of contractions during the initial two minute recording period for the test group of subjects and controls is shown in Table I. There was no significant difference between the test group and the controls during this baseline period.

Distension of the gall bladder for two minutes produced a significant decrease in basal pressure $(p=0.01, n=5 ;$ Fig 2 and Table II) and in the frequency of contractions $(p=0 \cdot 003, n=5 ;$ Fig 3 and Table II). When the saline in the gall bladder was aspirated the basal pressure increased significantly $(p=0.016, n=5$; Fig 2 and Table II), but the frequency of contractions was not significantly different from the frequency during the distension of the gall bladder (Fig 3 and Table II). During the period of gall bladder distension the intraluminal gall bladder pressure was $18 \cdot 5(3 \cdot 1) \mathrm{mmHg}(\mathrm{n}=4)$.

The alteration in basal pressure and frequency for the study group was significantly different from the alteration of basal pressure and frequency of the control group during the same period of time ( $\Delta$ basal pressure: $-4 \cdot 2(2 \cdot 4) v$ $-0.14(4.2), p=0.05$ and $\Delta$ frequency: -1.5 $(0.6)$ v $0.1(1.0), \mathrm{p}=0.007)$. There were no significant alterations in cardiovascular parameters during the test period. The pulse rate was 111 (21) beats/min during the baseline period and 109 (17) beats/min during the period of gall bladder distension. The systolic blood pressure was 125 (4) $\mathrm{mmHg}$ initially and 117 (3) $\mathrm{mmHg}$ in response to the distension of the gall bladder.

\section{Discussion}

The results of this study in humans have shown that distension of the gall bladder alters sphincter of Oddi motility. A decrease in sphincter of Oddi basal pressure and inhibition of sphincter of Oddi contraction frequency was produced. When the gall bladder was re-emptied the basal pressure returned to the value before the gall bladder distension but the frequency did not recover appreciably during the period of observation. These results are consistent with observations in animal studies, which suggests a reflex between the gall bladder and the sphincter of Oddi.

TABLE II Basal pressure and frequency of contractions

\begin{tabular}{lrrr}
\hline \multicolumn{3}{l}{ Gall bladder } & \\
\cline { 2 - 4 } & Empty & Distended & Re-emptied \\
\hline Basal pressure (mmHg) & $22 \cdot 8(8 \cdot 5)$ & $18 \cdot 6(6 \cdot 5)^{\star}$ & $21 \cdot 4(7 \cdot 2) \dagger$ \\
Frequency & $2 \cdot 6(1 \cdot 6)$ & $1 \cdot 2(1 \cdot 3)^{\star}$ & $1 \cdot 8(2 \cdot 9) \ddagger$ \\
(contractions/min) & & & \\
\hline
\end{tabular}

$\mathrm{p}<0.01$ compared with the results, with empty gall bladder, $+\mathrm{p}<0.01$ and $\neq$ not significant compared with the results with $\dagger<0.01$ and $\ddagger$ not signifi
distended gall bladder. distended gall bladder.
Values are mean $(\mathrm{SD})$.

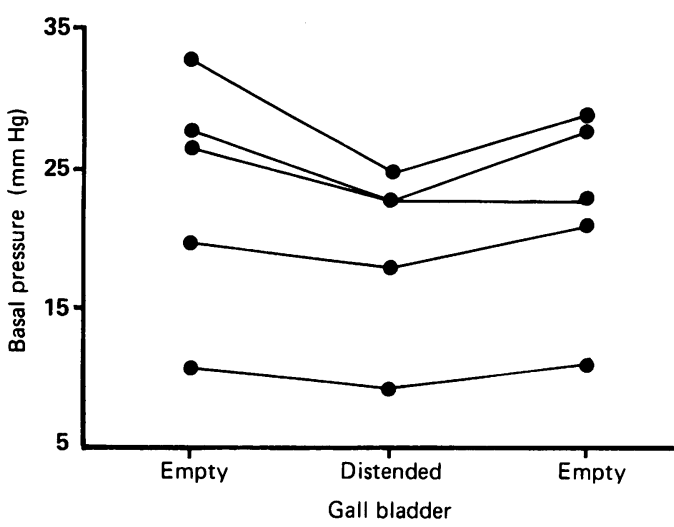

Figure 2: The sphincter of Oddi basal pressure $(\mathrm{mmHg})$ with the gall bladder empty, distended, and then re-emptied. Results are shown for the five patients studied.

Sphincter of Oddi mamometry was conducted in patients undergoing elective cholecystectomy for gall bladder stones. Previous studies have shown that non-opiate anaesthesia does not appreciably alter the motility of the sphincter of Oddi when compared to endoscopic manometry. To determine whether the changes in sphincter of Oddi motility observed in this study occurred spontaneously, a separate group of controls were studied under similar conditions; however, in these patients, the gall bladder was not distended. There were no significant alterations in sphincter of Oddi basal pressure nor contraction frequency during the same period.

Before distension of the gall bladder the bile was aspirated by placing a catheter into the fundus. A recording of sphincter of Oddi pressure was made with the gall bladder empty, then distension was achieved by reintroducing a volume of normal saline similar to the volume of aspirated bile. In addition, in all but one patient the gall bladder pressure was recorded, thus ensuring that overdistension did not occur. ${ }^{12}$ The pressures recorded in the gall bladder after distension were similar to those seen in experimental animals after ingestion of food. ${ }^{13} 14$ This further shows that overdistension was not produced. The technique used ensures that the degree of gall bladder distension produced would have been similar to that normally occurring in the patient. Hence, we believe that the changes of sphincter of Oddi motility recorded are consistent with the normal response

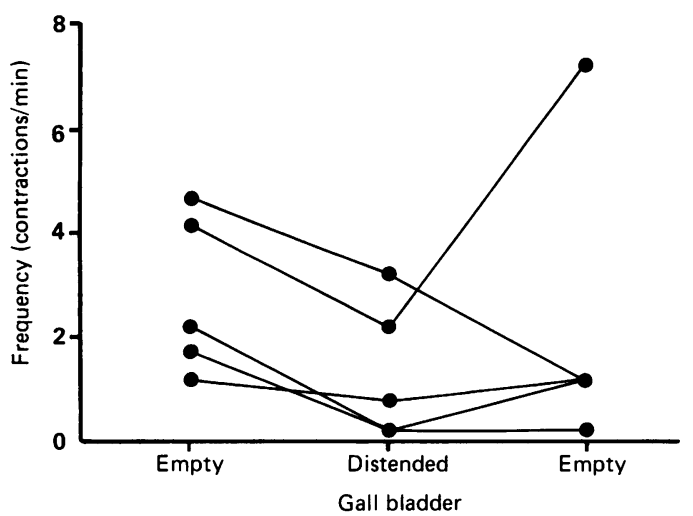

Figure 3: The frequency of sphincter of Oddi contractions (contractions/min) with the gall bladder empty, distended, and then re-emptied. Results are shown for the five patients studied. 
of the human sphincter of Oddi to increased gall bladder pressure on distension. Upon reemptying the gall bladder the fall in sphincter of Oddi basal pressure recovered. The frequency, however, did not return to the pre-gall bladder distension values for all patients during the time of observation. It is probable that with longer observation the frequency would have returned to the predistension value. The result in this study reflects one of the limitations of studies carried out intraoperatively, in that the observation time is limited.

A similar response of sphincter of Oddi motility to gall bladder distension has been previously reported in the cat. ${ }^{5}$ In addition, electrical and mechanical stimulation of the canine gall bladder has been shown to reduce the resistance to flow across the sphincter of Oddi. ${ }^{6}$ In these species the response would enhance flow across the sphincter of Oddi. In humans a decrease in basal pressure and inhibition of contraction frequency has similar effects. Cholecystokinin is known to enhance flow of bile into the duodenum ${ }^{12}$ and its effect on the sphincter of Oddi is a decrease of basal pressure and inhibition of the contraction frequency. ${ }^{15}$ Similarly, ingestion of food causes a fall in sphincter of Oddi basal pressure and decrease in the amplitude and duration of contractions. ${ }^{16}$ These effects are believed to enhance the flow of bile across the sphincter of Oddi into the duodenum.

The mechanisms for the reflex between the gall bladder and sphincter of Oddi in humans are unknown. In the cat it has been shown that the reflex may be abolished by adminstration of tetrodotoxin and by application of local anaesthetic to the region between the gall bladder and the sphincter of Oddi. ${ }^{5}$ These effects suggest that in the cat the reflex may be mediated by a neural mechanism. Morphological studies in guinea pigs have shown neural connections between the gall bladder and the sphincter of Oddi, ${ }^{9}$ and recent studies in the Australian possum have confirmed these observations. ${ }^{17}$ Whether similar neural connections exist in humans has not been shown. It would be expected, however, that the reflex as shown in this study is most likely to be neurally mediated as it occurs rapidly after gall bladder distension. On the other hand, the slow recovery of the response suggests that hormonal mechanisms may also be involved. Future studies will need to resolve the control mechanisms underlying these responses.

Sphincter of Oddi and gall bladder motility are influenced by changes in activity of other areas of the gastrointestinal tract. In the prairie dog distension of the stomach produces changes in sphincter of Oddi resistance and gall bladder pressure. ${ }^{18}$ Similar effects occur with duodenal and pancreatic duct distension. ${ }^{8}$ Thus a series of reflexes seem to be involved in the regulation of sphincter of Oddi motility.

The findings of our study may have further importance in providing one possible mechanism for the pathophysiology in postcholecystectomy sphincter of Oddi dysfunction. Injury to nerves which control sphincter of Oddi motility may result in disordered function of the sphincter of Oddi which could lead to a persistently raised basal pressure. Such an effect may ultimately lead to the sphincter of Oddi manometric abnormalities which have been described for sphincter of Oddi dysfunction.

This study was supported by a grant from the National Health and Medical Research Council of Australia. AT was partly supported Medical Research Council of Australia. AT was partly sup
by the Swedish Institute and Swedish Research Council.

1 Behar J, Biancani P. Neural control of the sphincter of Oddi: physiologic role of enkephalins on the regulation of sphincter of Oddi motor activity. Gastroenterology 1984; 86: $134-41$.

2 Persson CGA. Dual effects on the sphincter of Oddi and gallbladder induced by stimulation of the right great splanchnic nerve. Acta Physiol Scand 1973; 87: 33443 .

3 Dahlstrand C, Dahlström A, Ahlman H. Adrenergic and VIPergic relaxatory mechanisms of the feline extrahepatic biliary tree. F Auton Nerv Syst 1989; 26: 97-106.

4 Dahlstrand C, Edin R, Dahlström A, Ahlman H. An in vivo model for the simultaneous study of motility of the gall bladder, sphincter of Oddi and duodenal wall in the cat. Acta Physiol Scand 1985; 123: 355-62.

5 Thune A, Thornell E, Svanvik J. Reflex regulation of flow resistance in the feline sphincter of Oddi by distending pressure in the biliary tract. Gastroenterology 1986; 91: pressure

6 Wyat AP. The relationship of the sphincter of Oddi to the stomach, duodenum and gall bladder. F Physiol 1967; 193: 225-43.

7 Muller EL, Lewinski MA, Pitt HA. The cholecysto-sphincter of Oddi reflex. F Surg Res 1984; 36: 377-83

8 Thune A, Friman S, Conradi N, Svanvik J. Functional and morphological relationships between the feline main pancreatic and bile duct sphincters. Gastroenterology 1990; 98: 758-65.

9 Mawe GW, Gershon MD. Structure, afferent innervation, and transmitter content of ganglia of the guinea pig gall bladder in relationship to the enteric nervous system. F Comp Neurol 1989; 283: 374-90.

10 Toouli J, Bushell M, Iannos J, Collinson T, Wearne J, Kitchen D. Peroperative sphincter of Oddi manometry: motility
disorder in patients with cholelithiasis. Aust $N Z \mathcal{J}$ Surg disorder in patients

11 Toouli J, Geenen JE, Hogan WJ, Dodds WJ, Arndorfer RC. Sphincter of Oddi motor activity: a comparison between patients with common bile duct stones and controls. Gastroenterology 1982; 82: 111-7.

12 Dodds WJ, Hogan WJ, Geenen JE. Motility of the biliary system. In: Schultz SG, ed. Handbook of physiology. The gastrointestinal system. Bethesda MD. American Physiological Society, 1989: 1070-4.

13 Itoh Z, Takahashi I. Periodic contraction of the canine gall bladder during the interdigestive state. Am $\mathcal{F}$ Physiol 1981; 240: G183-9.

14 Takahashi I, Kern MK, Dodds WJ, et al. Contraction pattern of opossum gall bladder during fasting and after feeding. Am f Physiol 1986; 250: G227-35.

15 Toouli J, Hogan WJ, Geenen JE, Dodds WJ, Arndorfer RC. Action of cholecystokinin octapeptide on sphincter of Odd basal pressure and phasic wave activity in humans. Surgery 1982; 92: 497-503.

16 Worthley CS, Baker RA, Iannos J, Saccone GTP, Toouli J. Human fasting and postprandial sphincter of Oddi motility. Br F Surg 1989; 76: 709-14.

17 Padbury RT, Furness JB, Kuramoto H, Baker RA, Toouli J. Direct neural projections from the duodenum to the gall birect neural projections from the duodenum to the gall
bladder and sphincter of Oddi. Gastroenterology 1990; 98: A379.

18 Webb TH, Lillemoe KD, Pitt HA. Gastrosphincter of Oddi reflex. Am $\mathcal{J}$ Surg 1988; 155: 193-8. 